\title{
UNIVERSITYOF BIRMINGHAM

\section{A qualitative study of the views of patients with human immunodeficiency virus and childhood trauma on the consent process for a neurocognitive and neuroimaging study}

\author{
Bates, Helen; Seedat, Soraya; Lester, Helen
}

DOI:

10.1017/S1463423613000443

License:

None: All rights reserved

\section{Document Version}

Publisher's PDF, also known as Version of record

Citation for published version (Harvard):

Bates, H, Seedat, S \& Lester, H 2014, 'A qualitative study of the views of patients with human immunodeficiency virus and childhood trauma on the consent process for a neurocognitive and neuroimaging study', Primary Health Care Research \& Development, vol. 15, no. 04, pp. 362-374.

https://doi.org/10.1017/S1463423613000443

Link to publication on Research at Birmingham portal

Publisher Rights Statement:

(c) Cambridge University Press 2013

Checked for repository 09/10/2014

\footnotetext{
General rights

Unless a licence is specified above, all rights (including copyright and moral rights) in this document are retained by the authors and/or the copyright holders. The express permission of the copyright holder must be obtained for any use of this material other than for purposes permitted by law.

- Users may freely distribute the URL that is used to identify this publication.

- Users may download and/or print one copy of the publication from the University of Birmingham research portal for the purpose of private study or non-commercial research.

- User may use extracts from the document in line with the concept of 'fair dealing' under the Copyright, Designs and Patents Act 1988 (?)

- Users may not further distribute the material nor use it for the purposes of commercial gain.

Where a licence is displayed above, please note the terms and conditions of the licence govern your use of this document.

When citing, please reference the published version.

Take down policy

While the University of Birmingham exercises care and attention in making items available there are rare occasions when an item has been uploaded in error or has been deemed to be commercially or otherwise sensitive.

If you believe that this is the case for this document, please contact UBIRA@lists.bham.ac.uk providing details and we will remove access to the work immediately and investigate.
} 


\title{
A qualitative study of the views of patients with human immunodeficiency virus and childhood trauma on the consent process for a neurocognitive and neuroimaging study
}

\author{
Helen Bates ${ }^{1}$, Soraya Seedat ${ }^{2}$ and Helen Lester ${ }^{3}$ \\ ${ }^{1}$ Department of Primary Care Clinical Sciences, University of Birmingham, Birmingham, England, United Kingdom \\ ${ }^{2}$ Professor, Department of Psychiatry, Stellenbosch University, Stellenbosch, South Africa \\ ${ }^{3}$ Professor, Department of Primary Care Clinical Sciences, School of Health and Population Sciences, University of \\ Birmingham, Birmingham, England, United Kingdom
}

\begin{abstract}
Aim: To investigate the informed consent experiences of women with human immunodeficiency virus (HIV) and childhood trauma involved in a neurocognitive and neuroimaging study. Background: There is no previous research on the consent process for people with both HIV and childhood trauma, conditions that are syndemic in South Africa. Research on the consent process for each individual condition has shown that individuals with either of these conditions may be vulnerable research participants. This study aimed to investigate the opinions of the women involved in order to refine future consent processes and ensure that they are appropriate for this population. Methods: A qualitative semi-structured interview was conducted with women from Khayelitsha township in South Africa involved in a cohort study on neurocognitive and neuroimaging outcomes in HIV and childhood trauma, who agreed to participate in an interview immediately following their final study appointment. Findings: Aspects most frequently commented upon by participants during the interview were community recruitment, incentives for participation, quality of information provided, and misunderstandings and unexpected events. The overarching finding was that of therapeutic misconception; participants expected, and highlighted as incentives for participation, health benefits that were not part of the study. A minority of participants reported discomfort from questions concerning their traumatic experiences. Despite this, the consent process was well received and there was good understanding of confidentiality issues and the voluntariness of participation. Conclusion: Full disclosure of true benefits from participation must be emphasised throughout the recruitment process. This is particularly important for participants with HIV who appear to participate because of perceived health incentives. Providing prior notification that questions about traumatic experiences will be asked may improve the experiences of participants. A generic but thoroughly conducted consent process is suitable in this population.
\end{abstract}

Key words: childhood trauma; human immunodeficiency virus; informed consent; qualitative

Received 29 April 2013; revised 22 September 2013; accepted 14 October 2013;

first published online 19 November 2013

Correspondence to: Helen Bates, Room 126, 90 Vincent Drive, School of Health and Population Sciences, University of Birmingham, Birmingham, B15 2SP. Email: HLB959@bham.ac.uk

(C) Cambridge University Press 2013 


\section{Introduction}

Human immunodeficiency virus (HIV) is a large burden for South Africa with $17.3 \%$ of the population infected in 2011 (Shisana et al., 2009). This burden has prompted much research, the advancement of new therapeutics, and investigation of co-existing factors that contribute to poorer outcomes. One co-morbidity currently under investigation is childhood trauma (CHT). CHT is defined as 'a repeated pattern of damaging interactions between parent(s) [or other significant adults] and child that becomes typical of the relationship' (Dunsmore, 2013). Such traumas lie at the root of many psychiatric disorders (Murray, 2008) and, in HIV, may compound neurocognitive deficits and dementia resulting from HIV alone.

The context for this research impetus is a country still recovering from the turmoil of apartheid, abolished in 1994 (Choksi et al., 1995; King, 2010), where many black South Africans remain trapped in a vicious circle of poor education and poverty and have become confined by means to informal settlements (Myer et al., 2004). This situation coupled with a previously poorly funded public health system has exacerbated the spread of many diseases but particularly HIV (Myer et al., 2004). For this reason most of the study populations for HIV research in South Africa are composed of black individuals from poor socio-economic backgrounds and the growing volume of research should be underpinned by assurance that it is not exploitative of a medically and economically vulnerable group.

Ethical regulations give research participants rights to autonomy, beneficence, non-malfeasance and justice (World Medical Association, 2008). Potential participants must also be given appropriate information about the study before agreeing to participate (Abdool Karim et al., 1998; World Medical Association, 2008). Consent to participate is only valid if it is 'informed consent'. Informed consent is a process by which the research team and participant ensure that the participant is competent to make decisions, has had the research procedure explained, has understood the procedure, and has come to a voluntary decision (Jefford and Moore, 2008). Although informed consent is always important, it is particularly crucial for research involving vulnerable people, for example those with both HIV and CHT.
Both HIV and CHT sufferers have been described as vulnerable in research (Veatch, 1997; Faden and Kass, 1998; Mugisha et al., 1998; Seedat et al., 2004; Newman et al., 2006; Newman and Kaloupek, 2009). However, the combined impact of these two 'insults' on vulnerability has not been explored. Several reasons for vulnerability in HIV have been suggested (Abdool Karim et al., 1998; Rankin et al., 2005) but how to address these vulnerabilities to improve the consent process for research involving participants with HIV remains only partially explored. Similarly, it has been suggested that people with CHT may also be vulnerable in research because of the perceived power differential between researcher and participant (Yehuda, 2002; Newman and Kaloupek, 2009). Several studies have focused specifically on the ethical aspects of recruiting participants for research involving questions about traumatic experiences (Yehuda, 2002; Seedat et al., 2004; Newman and Kaloupek, 2009) and there is debate over the potential harms and benefits for participants (Yehuda, 2002; Seedat et al., 2004; Newman and Kaloupek, 2009). In this study we used qualitative methodology to provide insights into the informed consent process for people with both HIV and CHT.

\section{Methods}

\section{Design, rationale and setting}

This qualitative semi-structured interview study investigated participants' experiences of the consent process for a cohort study titled 'Neurocognitive outcomes in HIV and childhood trauma'. This cohort study aimed to identify neurocognitive interactions between HIV infection and CHT in women using: a clinician administered psychiatric diagnostic interview; neurocognitive testing to assess cognitive status; a blood test to provide a CD4 count; and an functional magnetic resonance imaging (fMRI) scan to facilitate an understanding of functional brain changes that underlie cognitive mechanisms in the context of these two conditions (Spies et al., 2012).

To assess participants' experiences of the consent process a qualitative approach was adopted to explore participants' individual experiences of an under-researched area (Sofaer, 1999). Individual interviews were favoured over focus groups 
because of the sensitive nature of the study and the difficulty of translating focus group transcripts. The study was conducted at the Faculty of Health Sciences, Tygerberg, South Africa.

\section{Recruitment}

Twenty five women, from Khayelitsha Township, were recruited immediately following their final study appointment. The aims of the interview were explained by a member of the study team to avoid the interviewer's presence influencing participants' decisions. Written consent was obtained using one of two trained Xhosa language interpreters.

Participants were all female, aged over 18 and had no history of major head trauma. The only additional criterion applied for the qualitative study was immediate termination of the interview if a participant became distressed. No participant was excluded on this criterion.

\section{Data collection}

Face-to-face interviews, following a topic guide, were conducted using an interpreter. The topic guide included four main themes derived from a literature review. It was piloted with a university student in October 2011 (Appendix 1). The pilot resulted in no major changes to the guide. Before each interview, the age, ethnicity and place of residence of the participant were recorded. All interviews were digitally recorded and English sections transcribed. One interpreter checked a selection of transcripts while listening to the recordings to identify any translation errors. None were found.

\section{Data analysis}

Data collection and analysis occurred concurrently. The interviewer transcribed all the recordings before coding them following Ritchie and Spencer 1994 Framework Analysis methodology (Bryman and Burgess, 2007). As suggested by Barbour (2001), coding of the initial five transcripts was conducted independently by H.B. and H.L. Coding was compared in detail and differences were discussed extensively and agreement reached over video-link. The remaining transcripts were coded by H.B. with regular review and discussion with H.L. Disconfirming evidence was sought throughout.
All interview transcripts were entered into $\mathrm{NVivo}_{9}$ to allow the analysis to be clearly documented at every stage of the process and to allow future researchers to revisit the original data and codes (Stake, 1995; Merriam, 1998). Charts were constructed for each theme after the 18th interview to ensure that any missed themes could be explored in the final interviews. The charting process was repeated after the final interviews. The interviewer also kept a reflective diary throughout the process as suggested by Watt (2007), including interactions with team members that influenced the 'mapping and interpretation' stage and allowed reflexivity (Glesne, 1999; Russell and Kelly, 2002).

\section{Results}

A total of 25 face-to-face interviews lasting 17-40 min took place between January and March 2012. All participants' home language was Xhosa.

Data saturation was reached by interview 20 . Opinions on the cohort study were mostly positive. Four themes were repeatedly raised: community recruitment; incentives for participation; quality of information provided; and misunderstandings and unexpected events. Quotations have been chosen on grounds of representativeness and presented in boxes with participant identification number and age.

\section{Community recruitment}

As a large number of participants meeting specific criteria were required in a short space of time, a large-scale community recruitment method was utilised for the cohort study. Recruiters contacted friends in the township and organised meetings at clinics and with established groups. In an area such as this, where many people live openly with HIV, informal recruitment could occur following the initial visits.

There was no evidence that this method caused any coercion to consent and it was generally regarded as a good method of informing large groups about research. The recruiters appeared to have a good understanding of the community's needs and to have presented the study in a clear and appealing way. Women felt comfortable being approached at both clinics and community groups and most reported that their family and 
Box 1 A selection of quotations about community recruitment for the cohort study

\begin{tabular}{|c|c|}
\hline \multirow[t]{3}{*}{$\begin{array}{l}\text { Group } \\
\text { recruitment }\end{array}$} & $\begin{array}{l}\text { I am also in a support group in Khayelitsha in one of the hospitals there whereby } \\
\text { HIV positive women are hanging together and supporting each other in the } \\
\text { group. And that is where I got informed and involved. } \\
(P 2-35 \text { years })\end{array}$ \\
\hline & $\begin{array}{l}\text { I did talk to a few friends and family. As a result some of my friends are also } \\
\text { interested to come and see as they are also diagnosed with HIV. } \\
(P 15-32 \text { years })\end{array}$ \\
\hline & $\begin{array}{l}\text { The reason I feel right in a group is because most of the time when you get told } \\
\text { something you get your own way of understanding certain things. And each } \\
\text { person has their own understanding. So when you go out of that place you can } \\
\text { advise each other and clarify to each other like this is what is happening. Rather } \\
\text { than being alone when you can miss some of the things, so it helps in a group } \\
\text { because the other people can tell you more. And maybe the other one who didn't } \\
\text { attend then him and the other person telling him he can understand exactly what } \\
\text { you were told. (P21 - } 32 \text { years) }\end{array}$ \\
\hline $\begin{array}{l}\text { Stigma of being } \\
\text { involved } \\
\text { in HIV research }\end{array}$ & $\begin{array}{l}\text {.. I can tell the whole world I am HIV positive so to me it wasn't what worried } \\
\text { me about how they told us in front of people but some of the people are still in } \\
\text { denial so they do not want people to know that they are HIV positive because } \\
\text { some of them they want to join the study, but they have been told the study is for } \\
\text { HIV positive so they go home and they didn't join the study. (P7 - } 48 \text { years) }\end{array}$ \\
\hline & $\begin{array}{l}\text { I was very free and relaxed the time the sisters spoke to us. The nurses weren't } \\
\text { talking to me in person, I overheard the conversation and I got interested and } \\
\text { that is how I did. They gave me interest also the way they were telling us all these } \\
\text { things, even advising us where to go and what to do. (P15-32 years) }\end{array}$ \\
\hline
\end{tabular}

friends were supportive of their participation although there was no sense that peer approval was required for participation. The community's knowledge and acceptance of most people's HIV status made community recruitment easier for this particular group. However, approximately a quarter of women reported that an acquaintance did not volunteer because they were unwilling to disclose their status (see Box 1).

\section{Incentives for participation}

The women indicated that they believed that there were both health and financial incentives associated with participation.

\section{Health incentives}

The expectation of health incentives mostly stemmed from the consent process. The women discussed the lack of resources at their local clinics; the majority preferring to visit the hospital because of the better care they received. All participants mentioned that a desire to understand and improve their own health was a motivating factor for their involvement. However, the women's responses indicate that information provided during the consent process may have inadvertently created false expectations of the benefits of participation.

The fMRI scan was a clear incentive for most of the women involved in the study. Women wanted to ensure that their brains were functioning normally and that they were 'mentally stable' (a translated term used to cover all descriptions of good mental aptitude). Interest in the scan was increased by knowledge of the impact HIV has on cognitive functioning. Over half the women expected to get results from the scan. However in 
reality, a woman would only be contacted in follow-up if her scan showed an obvious structural abnormality accompanied by significantly poor results in the neurocognitive assessment. Furthermore, a minority of women erroneously thought that the magnetic resonance imaging would assess their whole body. The majority of participants also indicated that they had expected to learn about HIV and to get advice about coping with the disease (see Box 2).

In contrast, the blood test was a significant incentive for participants which met expectations. A blood sample was taken on the first visit and the results were available at the final visit. This allowed the women to obtain their CD4 count. Women who did not have this checked regularly were able to see how their condition had progressed since diagnosis. Others who had just started treatment could see if they were benefitting from treatment before their next clinic appointment. Even women who were tested regularly felt reassured. In addition to the blood test, the opportunity to talk about their status and to be examined by the doctor relieved stress as access to doctors was limited locally (see Box 2).

\section{Financial incentives}

The women were given R100 (£8.33) for transport and a R100 supermarket voucher at the end of the study, a substantial gift for many of the participants who were living in poverty. Financial incentives were not routinely mentioned in the information at consent for fear that they could constitute undue influence to participate. The majority of women appeared unaware of the voucher but said that it would not have been an incentive to participate. A minority felt that advertisement of the vouchers would encourage participation. However, most indicated that the main incentive was to find out about their health rather than to gain financially.

Despite the primary incentive being a desire to know more about their health status, approximately a quarter of the women reported that the financing of transport to the hospital was essential and that receiving money after the first visit excluded people who were unable to raise the funds to attend that visit. Women suggested that provision of transport would improve their study experience (see Box 3).

\section{Quality of information provided}

The majority of women indicated that the explanation of the cohort study was satisfactory. Most had no questions, felt comfortable and expressed positive opinions about the information they were given. There was a good understanding of confidentiality and the voluntary nature of the research. However, over a third of participants were also unsure about what would happen and were surprised by some of the investigations.

Women reported that information provided at recruitment in the community was verbal. The majority were given a form to complete following a talk from the recruiters to identify women who had experienced CHT. Providing information through meetings was generally regarded as successful, however there were occasional reports of a shortage of forms. Several women explained that they were late for the meeting and missed some of the information, resulting in anxiety at Tygerberg. A minority of women reported that the recruiters had been late for the meeting and had insufficient time to explain the study fully.

Information provided during the consent process at Tygerberg was also verbal. Participants had the consent document explained to them and then signed the form. The protocol instructed the researchers to return the information parts of the form to the participant while retaining the signature sheets. However, the first 18 interviewees consistently reported that they were not given any written information. Many women felt that written information would have been helpful for personal records and to share with others. The lack of written information was brought to the attention of the research team and rectified immediately. Consequently, the final seven women interviewed all received written information. Despite this, some participants had not read it (see Box 4).

\section{Misunderstandings and unexpected events}

Despite the generally positive feedback about the explanation given during the consent process, there were three main areas of misunderstanding: the use of in-depth trauma questions; the fMRI process; and expectations of counselling.

Participants were frequently unaware that they would be questioned about their CHT. For the majority this was not a problem and they commented that it was easy to discuss things 
Box 2 A selection of quotations about the perceived health incentives of the cohort study
Preference of hospital care over care in clinics
It is very tough in our community now when it comes to the health care in the clinics, it is delayed so it takes so long and those people are too much lazy and sometimes you can wake up early early in the morning to go to the clinic but you have other priorities during the day and you could end up spending you whole day in the clinic ... Coming here I was so much impressed because everything went to time here they would tell you that at this certain time you will go here and at this time you will go to this place and after this place to this place and everything is on time... (P8 - 32 years)
Actually in all the clinics on the locations, there is no hospitality for us as patients compared with hospitals. I prefer the big hospitals, they show us so much hospitality. (P16 - 34 years)

Incentive of the fMRI scan

Blood test incentive
The scan that is what makes me part of the study... when I heard that there was going to be a scan that's what I wanted because a scan is so expensive going to a private doctor so for me that is what I wanted. (P1 - 38 years)

For me to be crazy about this study it was about number one going to the scan ... People who are HIV positive when it comes to them getting sick some of them get their meningitis and people think that they are crazy and some of the effects are like oozing coming out of the ear but for me I just wanted to get on the scan and get tested. (P2 - 35 years)

The most important thing that I saw was that there was a scanner process for you to check how my mentality is and that I am mentally stable and that there is nothing wrong with me and that everything is functioning in order. (P16 - 34 years)

The thing that made me want to be involved is that they are going to examine the brain and I was not going to be charged for that. (P26-42 years)

The lady was told me saying you are going to the scan they will check everything and they are going to tell us everything if there is anything that they find. (P8 - 32 years)

Now I heard about my CD4 count when I started ARVs last month ... when I last tested was in November and it was 295 so it was low so I had to start the $A R V$ s and I started last month, this January, so now they took my blood and my CD4 count has increased to 700 and something so by my clinic I would only have known in six months time. Then they will take my blood in six months time like I am just starting ARVs [Antiretroviral therapy] I do not know if my CD4 count is increasing or decreasing then like now I know that it did increase. (P3 - 34 years)

I wanted to know more about my own health, about my status and about my CD4 count and if there is any illness within that. (P6-36 years) pertaining to their own past lives. However, for others, the questioning brought back memories of traumatic events. For these individuals the probing questions caused acute discomfort.
The erroneous expectations of the fMRI results have been discussed in a previous section, but the women also reported fear of the fMRI process. The majority of participants commented on fear 
Box 3 A selection of quotations about the perceived financial incentives

Money incentive

Money is essential to facilitate participation
I wanted them [friends she recruited from the community] to participate because they are unemployed and at the same time there is that incentive of the voucher... I would be part of it even if there was no incentive. (P5 - 40 years)

Most people are coming for vouchers. Someone will hear from another person who received something like this and then that person will automatically want to come, just because she wants to get the same. In my opinion, that is what will happen in most cases. (P16 - 32 years)

I couldn't care less about the voucher! I wanted to find out what is going on with the HIV and the HIV patients ... There is not even a bit of me that thinks people will come for the vouchers, especially the HIV patients, because like they normally go to support groups which are away from their location and they must take transport on their own. Most of the support groups do not offer vouchers, so normally the HIV patients are just interested in wanting to know their status and their whereabouts with HIVI AIDS. (P15 - 26 years)

Some of them, they want to come here but they didn't have the money, the cash, to came here ... so money is only given on Wednesday [Study day] and if you don't have the money to come on Wednesday morning then you cannot come. (P6 - 36 years)

There are also other people but they do not have means to come here, or they do not have a way, a channel to come here ... I can't say really what is the problem. According to the way I see it, it is transport because I did experience suffering coming here in the morning yesterday. So the voucher I got in here yesterday helped me a lot to come back here again. It gave me more strength and eagerness to come. (P25 - 39 years)

Yes the people will love that [Provision of transport] because their only problem to come and attend these things is that they don't have money to go to the places or for transport. People love the studies, with money or no money. (P24 - 36 years) of the machine despite an explanation of what would happen and an awareness of their rights to withdraw at any point. However, when asked what they would tell a future participant about the process, the participants almost uniformly gave very similar advice to that provided to them before they entered the scanner.

Finally, over half of participants believed that they were entering this study to learn about HIV and to get advice about maintaining their health. In particular about a third of participants mentioned that they expected counselling about medication adherence. Counselling and health advice were not components of the cohort study. The expectation of these components highlights a misunderstanding of the information provided during the consent process (see Box 5).

\section{Discussion}

This study is believed to be the first to address the informed consent process for people with both HIV and CHT. The consent process was largely well 
Box 4 A selection of quotations about the participants' views on the quality of information provided during the cohort study

Satisfaction with information provided and confidentiality

Misunderstanding and anxiety

Written information
Everything was clear to me, right, so I didn't have any questions. ( $P 2-35$ years $)$

I felt confident because it was confidential because when I had to sign the form there was no one who had to look at the form and I only gave it to the sister, so I was quite alright with the whole signing of the form.

(P12 - 40 years)

All I can say is that I loved it. (P4 - 37 years)

Normally when I get called to the hospital I get worried sick and I stress too much because like I know that I am a patient and I know that everything that is coming from the hospital is about me, so I just worry too much. But I didn't expect anything or some sort. I was called to the hospital so I was just worried, that they would tell me something bad.

(P14 - 27 years)

The lady came, but it was very late, she couldn't tell us really about the study, but she requested that we give our phone numbers and she insisted that she is going to phone us according the study in Tygerberg ... They didn't tell me nothing ... I didn't know what to do, I was just scared. (P17 - 34 years)

I would love it [information about study] on written papers so that I could keep it. (P18 - 43 years)

I would prefer to get the information on paper, in a more written way so that I can read and understand.

(P14 - 27 years)

Yes there is a paper that she gave me, it is written in Xhosa, it is by my house now ... Yes, yes it was useful. It is like the very same things she asked me and the very same things that are written in the paper it did make sense to me. (P24 - 36 years)

I am quite alright with it [Written information], I haven't read it yet ... I was fine with the verbal information I was relieved because I got to connect with what she was saying. (P25 - 39 years) received. The aspects most frequently commented upon were: community recruitment; incentives for participation; quality of information provided; and misunderstandings and unexpected events.

\section{Comparison with previous research}

The use of community recruitment for the study was considered useful and women were comfortable with both group recruitment and the information delivered. There was no suggestion that coercion was present. As anticipated by Karwalajtys et al. (2010), recruiters being friends with members of the community, speaking a common language and having an awareness of cultural norms, increased trust in the study. Further exploration of the use of social networks for recruitment, particularly focusing on possible 
Box 5 A selection of quotations about the misunderstandings and unexpected events encountered by participants of the cohort study

Presence of unexpected questions about childhood trauma

Fear of the fMRI process

Erroneous expectations of what the study entailed
Maybe the other questions were unexpected so but it was nothing personal like something I feel to share with someone. So the questions were also fine. (P3 - 34 years)

I: So how did you feel when they started asking those questions?

P: I was like for a moment shocked but I was alright, and I answered back.

(P17 - 34 years)

I was the scared of the machine because I didn't know what the machine was about to do to me ... I was scared because I thought that they were going to put an injection on me. But then they explained that the machine is not going to do nothing to me just that I was to go in and listen to music ... They did explain to me before everything and it did happen to me as I was told. (P1 - 38 years)

The only time I was scared was when I went to the scan. (P4 - 37 years)

It was terrible [the scan experience], I can't breathe when they put this thing over my face and head and they laid me down and then they pushed me inside. I was afraid that I was going to die. (P11 - 43 years)

The sort of things I was expecting from this study was more like counselling and stuff. I like to talk and be free and accept my condition ... I expected that I would be empowered about my well being and I expected to learn about how to take care of myself. Things I must do and things I must not do, but mostly to be aware as a patient how to live and to survive. (P14 - 27 years)

I was told that they are going to check from the head to the toes as to if there is any illness in my body. (P4 - 37 years) coercion to consent, is an area for further research.

To provide consent, participants must be able to understand, weigh-up and retain the information given and then communicate their decisions (Kylma et al., 1999; Jefford and Moore, 2008). There is no evidence in the literature that experience of CHT or HIV infection reduces decisional capacity or susceptibility to coercion (Faden and Kass, 1998; Newman et al., 2006; Newman and Kaloupek, 2009). For these reasons the consent process was not specifically tailored for a group with both HIV and CHT. The acceptance of a generic consent process by the population supports this, indicating that future studies involving this population need not be hindered by a lack of specifically tailored consent procedures. However, signposting the use of questions about traumatic experiences in the consent process should be considered, supporting previous findings that reactions to these questions vary greatly between individuals (Seedat et al., 2004; Newman and Kaloupek, 2009).

Despite this overall acceptance, several participants expected benefits from the study that were beyond the true benefits, a situation of 
therapeutic misconception (Appelbaum et al., 2004). This common issue has been highlighted in previous research with some suggesting that there is a larger risk in research involving vulnerable participants (Lee et al., 2001; Appelbaum et al., 2004; Escobedo et al., 2007).

The main reason reported for participation was gaining information about health. The women received a CD4 count and were also examined by a doctor for signs of major illness. Mental wellbeing was assessed with a psychiatric diagnostic interview and participants with a diagnosed mental illness were referred to a psychiatric clinic for further evaluation. However, participants expected to receive HIV counselling, which was not a component of the study. Moreover, the majority of women believed the fMRI scan was used to assess mental well-being with over half expecting to receive results. The women felt that any abnormality would be identified but an in-depth investigation of participants' brains was never an aim of the study. The fMRI scans were examined as a group to investigate any structural factors that may underlie cognitive mechanisms in HIV and CHT. The identification of a major abnormality during research such as this is rare because of the focus and expertise of the researchers and the study aims (Mamourian, 2004; Hadskis et al., 2008).

These findings support a finding that therapeutic misconception is common in paediatric neuroimaging research (Hadskis et al., 2008). Moreover, they reinforce empirical evidence showing that people with poorer health and are at a greater risk of therapeutic misconception (Appelbaum et al., 2004). Therapeutic misconception has also been identified as a possible complication of research in Sub-Saharan Africa because of recent advances in health care and the accompanying increased research activity combined with the high social status of researchers in communities with a low standard of education (Fitzgerald et al., 2002; Yousuf et al., 2007; Ogwuegbu and Eze, 2009; Halverson and Ross, 2012). This may have been a contributing factor in this study.

Secondary to this, participants in research often want to believe that participation leads to additional benefits (Lema, 2009). This has been demonstrated in early phase trials for novel cancer therapies (Jansen, 2011) and may also impact people suffering from chronic infections such as HIV. Thus in this study the therapeutic misconception identified may have been a bidirectional problem of a lack of pertinent information in the consent process and participants wanting someone to be helping them, as suggested by Lema (2009). This 'therapeutic optimism' - a hope of identification of a cure through the study investigations despite a high improbability - can exist even using the optimum consent procedure (Horng and Grady, 2003). Complete elimination of therapeutic optimism may be an ethical ideal which is impossible to meet. However, provision of clearer information at consent about the true benefits, and fuller explanation of the aims of investigations could lessen the risk of therapeutic misconception in future studies.

Participants' understanding of the study may also have been compromised by the lack of written information during the first 18 interviews. The misunderstandings may indicate that the provision of retainable information would have been beneficial. The use of audio-recorded information at consent has improved patients' understanding in previous research (Lloyd et al., 2008). Given that half of the participants who received written information reported having not read it, or preferred the verbal explanation, this method could be considered for future studies.

\section{Limitations}

This was a small study involving 25 short interviews in one location. Our findings are site specific, and caution should be exercised in making generalisations to other locations. However, in relation to validity, care was taken in the initial analysis to ensure the development and consistent use of a coding framework grounded in the data that was available. The parent study, and consequently this study, drew its participants from an area of severe deprivation and from a community very open about HIV status. Such acceptance may not be generalisable to other township communities in South Africa. A further limitation was one of language: the use of interpreters added a risk of data being lost or misconstrued despite attempts to mitigate this. As translated interviews were used as data, some ethnically relevant terms may not have been conveyed effectively by English equivalents. 
Use of interpreters also prevented the use of focus groups which could have provided triangulation of data as well as allowing participants to interact with each other. Triangulation through other methods was not possible due to time constraints.

Despite these limitations, this study had a tangible impact on the parent study. Future studies could minimise these limitations by deploying bilingual interviewers to avoid the issues of translation; including a larger and/or broader sample size and including methods to provide triangulation of data.

\section{Summary}

This study is believed to be the first on the consent process for people with both HIV and CHT. As such, it provides a useful baseline for future research. It highlights, in particular, the risks of therapeutic misconception unless special care is taken during the consent process.

Despite its size this study had a measurable impact on the 'Neurocognitive outcomes in HIV and childhood trauma' cohort study. It has supported previous research indicating that a generic consent process is appropriate for participants with both HIV and CHT. However, this study has also highlighted the importance of full explanation of the benefits to participants of any investigations carried out during the research and emphasises the importance of providing retainable information during the consent process. Above all, participants appreciated the opportunity to be involved in research and were mostly content with the consent process for this cohort study.

\section{Acknowledgements}

The authors are grateful to all the women who contributed to this study; Dr Spies for her support and advice; Nonkutalo and Lettica Hinsho for their work in recruitment and testing; Lindile Khetelo and Mzukisi Mnene for their advice and interpretation work; Julie Shore and Sarah Hinton for their administrative help; and Dr George Dowswell and Dr Jonathan Ives for their advice on redrafting the paper. This paper is dedicated to the memory of Helen Lester who sadly passed away before its completion and publication.

\section{Financial Support}

This work was supported by the South African Research Chairs Initiative and the National Research Foundation (Department of Psychiatry, Stellenbosch University) and the Arthur Thompson Fund.

\section{Conflicts of Interest}

None.

\section{Ethical Standards}

Approval was obtained from the University of Birmingham Internal Ethics Review Committee (November 2011) and the University of Stellenbosch Health Research Ethics Committees (reference number S11/12/052). All participants provided written informed consent and any details that could allow identification of participants have been changed to protect their identity.

\section{References}

Abdool Karim, Q., Abdool Karim, S., Coovadia, H.M. and Susser, M. 1998: Informed consent for HIV testing in a South African hospital: is it truly informed and truly voluntary? American Journal of Public Health 88, 637-40.

Appelbaum, P.S., Lidz, C.W. and Grisso, T. 2004: Therapeutic misconception in clinical research: frequency and risk factors. IRB: Ethics \& Human Research 26, 1-8.

Barbour, R.S. 2001: Checklists for improving rigour in qualitative research: a case of the tail wagging the dog? British Medical Journal 322, 111-117.

Bryman, A. and Burgess, R. (editors) 2007: Analysing qualitative data, first edition. New York: Routledge.

Choksi, M., Carter, C., Gupta, D., Martain, T. and Allen, R. 1995: The history of apartheid in South Africa. Stanford online. Retrieved 28 June 2013 from http://www-csstudents.stanford.edu/ cale/cs201/apartheid.hist.html

Dunsmore, J. 2013: What is childhood trauma? National Association for Loss and Grief. Retrieved 28 June 2013 from http://www.nalag.org.au/pubs/b_buddy_files/bbuddy\%202013/ Bereavement \%20Buddy\%20February\%202013.pdf

Escobedo, C., Guerrero, J., Lujan, G., Ramirez, A. and Serrano, D. 2007: Ethical issues with informed consent. USA: E-zine: youth scientists and the ethos of current science. Retrieved 13 February 2013 from http://cstep. cs.utep.edu/research/ezine/Ezine-EthicalIssueswithInformed Consent.pdf

Faden, R. and Kass, N. 1998: HIV research, ethics, and the developing world. American Journal of Public Health 88, 548-50. 
Fitzgerald, D.W., Marotte, C., Verdier, R.I., Johnson, W.D. Jr. and Pape, J.W. 2002: Comprehension during informed consent in a less-developed country. Lancet 360, 1301-302.

Glesne, C. 1999: Becoming qualitative researchers: an introduction, second edition. USA: Allyn \& Bacon.

Hadskis, M., Kenny, N., Downie, J., Schmidt, M. and D'Arcy, R. 2008: The therapeutic misconception: a threat to valid parental consent for pediatric neuroimaging research. Accountability in Research 15, 133-51.

Halverson, C.M. and Ross, L.F. 2012: Incidental findings of therapeutic misconception in biobank-based research. Genetics in Medicine 14, 611-15.

Horng, S. and Grady, C. 2003: Misunderstanding in clinical research: distinguishing therapeutic misconception, therapeutic misestimation, and therapeutic optimism. IRB 25, 11-16.

Jansen, L.A. 2011: Two concepts of therapeutic optimism. Journal of Medical Ethics 37, 563-66.

Jefford, M. and Moore, R. 2008: Improvement of informed consent and the quality of consent documents. The Lancet Oncology 9, 485-93.

Karwalajtys, T.L., Redwood-Campbell, L.J., Fowler, N.C., Lohfeld, L.H., Howard, M., Kaczorowski, J.A. and Lytwyn, A. 2010: Conducting qualitative research on cervical cancer screening among diverse groups of immigrant women: research reflections: challenges and solutions. Canadian Family Physician 56, e130-35.

King, C.E. 2010: South African Science: signs of progress. Thompson Reuters. Retrieved 28 June 2013 from http:// archive.sciencewatch.com/ana/fea/10mayjunFea/

Kylma, J., Vehvilainen-Julkunen, K. and Lahdevirta, J. 1999: Ethical considerations in a grounded theory study on the dynamics of hope in HIV-positive adults and their significant others. Nursing Ethics 6, 224-39.

Lee, S.J., Fairclough, D., Antin, J.H. and Weeks, J.C. 2001: Discrepancies between patient and physician estimates for the success of stem cell transplantation. The Journal of the American Medical Association 285, 1034-038.

Lema, V.M. 2009: Therapeutic misconception and clinical trials in sub-Saharan Africa: a review. East African Medical Journal 86, 291-99.

Lloyd, C.E., Johnson, M.R., Mughal, S., Sturt, J.A., Collins, G.S., Roy, T., Bibi, R. and Barnett, A.H. 2008: Securing recruitment and obtaining informed consent in minority ethnic groups in the UK. BMC Health Services Research 8, 68-69

Mamourian, A. 2004: Incidental findings on research functional MR images: should we look? American Journal of Neuroradiology 25, 520-22.

Merriam, S. 1998: Qualitative research and case study applications in education, first edition. USA: Jossey-Bass.

Mugisha, E., Kabugo, M. and McGrath, J.E.A. 1998: Perceived stigma associated with participation in HIV vaccine trials in Uganda. International AIDS Conference 12, 238.
Murray, B. 2008: Childhood trauma. Uplift programme. Retrieved 28 June 2013 from http://www.upliftprogram. com/facts_childhood_trauma.html

Myer, L., Ehrlich, R.I. and Susser, E.S. 2004: Social epidemiology in South Africa. Epidemiologic Reviews 26, 112-23.

Newman, E. and Kaloupek, D. 2009: Overview of research addressing ethical dimensions of participation in traumatic stress studies: autonomy and beneficence. Journal of Traumatic Stress 22, 595-602.

Newman, E., Risch, E. and Kassam-Adams, N. 2006: Ethical issues in trauma-related research: a review. Journal of Empirical Research on Human Research Ethics 1, 29-46.

Ogwuegbu, C.C. and Eze, O.H. 2009: Ethical and social issues facing obstetricians in low-income countries. Clinical Obstetrics and Gynecology 52, 237-49.

Rankin, W.W., Brennan, S., Schell, E., Laviwa, J. and Rankin, S.H. 2005: The stigma of being HIV-positive in Africa. PLoS Medicine 2, e247.

Russell, G. and Kelly, N. 2002: Research as interacting dialogic processes: implications for reflexivity. Forum: Qualitative Social Research 3, 18.

Seedat, S., Pienaar, W.P., Williams, D. and Stein, D.J. 2004: Ethics of research on survivors of trauma. Current Psychiatry Reports 6, 262-67.

Shisana, O., Rehle, T., Simbayi, L.C., Zuma, K., Jooste, S., Pillay-van-Wyk, V., Mbelle, N., Van Zyl, J., Parker, W., Zungu, N.P. and Pezi, S., and the SABSSM III Implementation Team. 2009: South African national HIV prevalence, incidence behaviour and communication survey 2008: a turning tide among teenagers? Cape Town: HSRC Press.

Sofaer, S. 1999: Qualitative methods: what are they and why use them? Health Services Research 34: 1101-118.

Spies, G., Cherner, M., Fennema-Notestine, C., Archibald, S. and Seedat, S. 2012: Neurocognitive deficits in HIV-infected women and victims of childhood trauma. AIDS Care 24, 1126-135.

Stake, R. 1995: The art of case study research. USA: Sage.

Veatch, R. (editor) 1997: Medical ethics, second edition. United Kingdom: Jones and Barlett Publishers.

Watt, D. 2007: On becoming a qualitative researcher: the value of reflexivity. The Qualitative Report 12, 82-101.

World Medical Association. 2008: Declaration of Helsinki, ethical principles for medical research involving human subjects, initiated 1964, last amendment 2008. World Medical Association. Retrieved 28 June 2013 from http:// www.wma.net/en/30publications/10policies/b3/

Yehuda, R. 2002: Post-traumatic stress disorder. The New England Journal of Medicine 346, 108-14.

Yousuf, R.M., Fauzi, A.R., How, S.H., Rasool, A.G. and Rehana, K. 2007: Awareness, knowledge and attitude toward informed consent among doctors in two different cultures in Asia: a cross-sectional comparative study in Malaysia and Kashmir, India. Singapore Medical Journal 48, 559-65. 


\section{Appendix 1}

This topic guide is to be used in a study to ascertain the views of women with HIV and childhood trauma in South Africa on the consent process for a research project. The semistructured interviews followed this guide. The interviews did not necessarily use this exact wording but each included discussion of all the topic headings.

Opinions on the consent procedure

1. Could you describe in your own words how you became involved in the research?

For this question the aim is to discover: why participants were willing to get involved; if they spoke to anyone about the project and how they felt after agreeing to be involved. The following prompts may be used to probe answers further:

○ Why were you willing to get involved?

- Who did you talk to about participating in this research project?

-When you signed the form how did you feel?

Information provided

2. What information were you given about the study?

For this question the aim is to discover: how easy the information was to understand; if any questions were asked about the process and how participants felt about questioning the researchers if they did. Also to try and determine if participants became concerned during the study and if so, how this was resolved. The following prompts may be used to probe answers further

$\circ$ Was the information easy to read?

- Was the information easy to understand?

- Did you get an opportunity to ask questions?

- How did you feel about asking the researchers questions?

$\circ$ Did any questions or concerns emerge during the research?
- How did you deal with these concerns?

- Did you feel able to pull out of the research?

- Was it clear that you could withdraw at anytime?

Surprises

3. Was any part of the research project not what you expected it to be?

This question aims to determine how participants felt about the research; if anything happened that they were not expecting and how they felt during the investigations. The following prompts may be used to probe answers

- On the morning of each of you appointments, can you tell me how you felt?

- Were any of the investigations done as part of the research not how you expected?

- How did you find the MRI scan?

- How did the questionnaires make you feel?

Improvements

4. If you were to change the consent procedure for this study, is there anything you would have done differently?

This question seeks to identify if any changes could be made to the process of consent to make it better. This could involve changing the length of appointments, altering the explanation or making the information more accessible. The following probing questions may be used

- Could the length of any of the appointments been changed?

- Would you alter the explanation of the study?

- Could the information given about the study be made more accessible?

\section{Conclusion}

5. Is there anything else you would like to tell me? All the answers you have provided will be completely anonymous and stored securely. Thank you for giving up your time to help with this research. 